Corrigendum: Post-study caffeine administration enhances memory consolidation in humans

Daniel Borota, Elizabeth Murray, Gizem Keceli, Allen Chang, Joseph M Watabe, Maria Ly, John P Toscano \& Michael A Yassa Nat. Neurosci. 17, 201-203; published online 12 January 2014; corrected online 17 January 2014; corrected after print 30 June 2014

In the version of this article initially published, there were errors in the reporting of statistics. In the Figure $1 \mathrm{~b}$ legend, the asterisked $P$ value was given in the HTML version as ${ }^{\star} P=0.05$ and in the $\mathrm{PDF}$ version as ${ }^{\star} P<0.05$. It should read ${ }^{\star} P<0.05$, one-tailed. In the Figure $2 \mathrm{a}$ legend, the degrees of freedom for the immediate caffeine group were given as 42 and the $P$ value as 0.05 ; the correct values are 71 and 0.049 , respectively. In the Figure $2 \mathrm{~b}$ legend and the fifth paragraph of the main text, the $P$ value for the main effect of caffeine was given as 0.001 ; the correct value is 0.05 . The errors have been corrected in the HTML and PDF versions of the article.

\title{
Corrigendum: LRRK2 regulates synaptogenesis and dopamine receptor activation through modulation of PKA activity
}

Loukia Parisiadou, Jia Yu, Carmelo Sgobio, Chengsong Xie, Guoxiang Liu, Lixin Sun, Xing-Long Gu, Xian Lin, Nicole A Crowley, David M Lovinger \& Huaibin Cai

Nat. Neurosci. 17, 367-376 (2014); published online 26 January 2014; corrected after print 27 February 2014

In the version of this article initially published, the G2385R mutation in Figure 7a,b was given as G2835R. The error has been corrected in the HTML and PDF versions of the article.

\section{Corrigendum: LRRK2 regulates synaptogenesis and dopamine receptor} activation through modulation of PKA activity

Loukia Parisiadou, Jia Yu, Carmelo Sgobio, Chengsong Xie, Guoxiang Liu, Lixin Sun, Xing-Long Gu, Xian Lin, Nicole A Crowley, David M Lovinger \& Huaibin Cai

Nat. Neurosci. 17, 367-376 (2014); published online 26 January 2014; corrected after print 27 February 2014; corrected after print 18 June 2014

Initial version

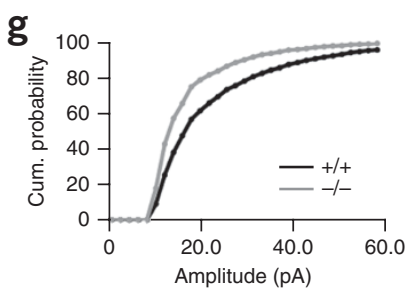

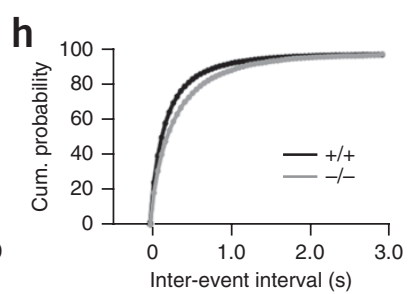

Corrected version
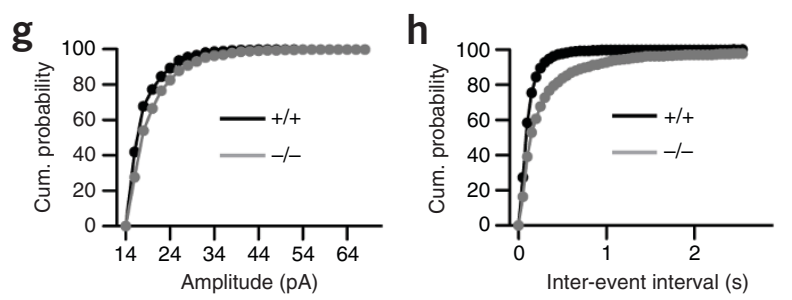

In the version of this article initially published, the line graphs presented in Figure 1g,h were switched with ones from a different experiment. The error has been corrected in the HTML and PDF versions of the article.

\section{Erratum: Peripheral gating of pain signals by endogenous lipid mediators}

Daniele Piomelli \& Oscar Sasso

Nat. Neurosci. 17, 164-174 (2014); published online 28 January 2014; corrected after print 18 March 2014

In the version of this article initially published, the phosphoanandamide in Figure 3a terminated in a hydroxyl instead of a phosphate group. The error has been corrected in the HTML and PDF versions of the article.

\section{Erratum: Orbitofrontal activation restores insight lost after cocaine use}

Federica Lucantonio, Yuji K Takahashi, Alexander F Hoffman, Chun Chang, Sheena Bali-Chaudhary, Yavin Shaham, Carl R Lupica \& Geoffrey Schoenbaum

Nat. Neurosci. 17, 1092-1099 (2014); published online 20 July 2014; corrected after print 28 July 2014

In the version of this article initially published, author Chun Yun Chang's name was given as Chun Chang. The error has been corrected in the HTML and PDF versions of the article. 